\title{
A Review of Chronic Musculoskeletal Pain: Central and Peripheral Effects of Diclofenac
}

Fabiola Atzeni · Ignazio Francesco Masala · Piercarlo Sarzi-Puttini

Received: August 30, 2017 / Published online: June 5, 2018

(C) The Author(s) 2018

\section{ABSTRACT}

Diclofenac is widely used to manage chronic inflammatory and degenerative joint diseases such as osteoarthritis (OA), rheumatoid arthritis (RA), ankylosing spondylitis, and extra-articular rheumatism. Its various mechanisms of action make it particularly effective in treating nociceptive pain, but it is also an alternative for treating spinal and chronic central pain. Osteoarthritis and rheumatoid arthritis are the most frequently encountered arthritic conditions in adults. The management of nociceptive pain requires a sequential hierarchical approach, with the initial NSAID treatment being characterized by the replacement of one

Enhanced digital features To view enhanced digital features for this article go to https://doi.org/10.6084/ m9.figshare.6061397.

Fabiola Atzeni and Ignazio Francesco Masala contributed equally to this paper.

F. Atzeni $(\bowtie)$

Rheumatology Unit, University of Messina,

Messina, Italy

e-mail: atzenifabiola@hotmail.com;

fatzeni@unime.it

I. F. Masala

Orthopedic and Trauma Unit, Santissima Trinità

Hospital, Cagliari, Italy

P. Sarzi-Puttini

Rheumatology Unit, L. Sacco University Hospital, Milan, Italy drug with another, or complete discontinuation usually because of insufficient pain control. OAand RA-related pain is complex and multifactorial, and due to physiological interactions between the signaling of the central and peripheral nervous systems. The mechanisms of action of diclofenac make it particularly effective in treating both nociceptive pain and chronic central pain. This review underlines the mechanisms of diclofenac involved in chronic and acute joint pain, the most relevant adverse events.

Keywords: Chronic pain; Diclofenac; Musculoskeletal pain; NSAIDs; Spinal pain

\section{INTRODUCTION}

Diclofenac, ibuprofen, and ketoprofen are nonsteroidal anti-inflammatory drugs (NSAIDs) that have been widely used to manage chronic inflammatory and degenerative joint diseases and treat pain for the last 30 years. Their multifactorial anti-inflammatory and analgesic activities not only involve cyclo-oxygenase (COX) inhibition, but also a series of pain and inflammatory mediators and intracellular pathways.

Diclofenac (2-[2,6-dichloranilino]phenylacetic acid) is available in oral sodium, potassium, sodium/misoprostol, and 
hydroxyethylpyrrolidine formulations, and is indicated for the treatment of osteoarthritis (OA), rheumatoid arthritis (RA), ankylosing spondylitis, extra-articular rheumatism, and postoperative pain [1]. Its main mechanism of analgesic action is COX inhibition, which decreases the production of prostaglandin E2 (PGE2) and thromboxane, but it also has other peripheral and central mechanisms $[2,3]$.

The aim of this review is to underline the mechanisms of actions of diclofenac subdivided into well-known and then recently discovered mechanisms of action. Furthermore, the mechanisms responsible for the acute and chronic pain in rheumatoid arthritis and in osteoarthritis and the management of pain have been described.

\section{MECHANISMS OF ACTION}

This article is based on previously conducted studies and does not contain any studies with human participants or animals performed by any of the authors.

\section{Well-Known Mechanisms}

\section{Peripheral Mechanisms}

Various in vitro models and in vivo tissue studies have shown that NSAIDs inhibit prostaglandin and thromboxane synthesis [3], but it has been reported that the efficacy of diclofenac in inhibiting blood and synovial tissue COX levels (and consequently the synthesis of proinflammatory and nociceptive prostaglandins) $[4,5]$ is $3-1000$ times that of other NSAIDs [6], and that its inhibition of PGE2 correlates with plasma drug levels [7].

COX has two distinct isoforms [8]: COX-1 is constitutively and relatively stably expressed in most tissue types, where it mediates normal platelet function, regulates renal blood flow, and cytoprotects the gastric mucosa by means of prostaglandin I2 (prostacyclin) [8]; COX-2 expression increases in the presence of damaged tissue and pro-inflammatory mediators, which increases the production of the prostaglandin, thromboxane, and leukotriene mediators of inflammation and pain [8]. Diclofenac is four times more selective for COX-2 than other NSAIDs but, as pointed out by Warner et al. [9], therapeutic concentrations (i.e., $\mathrm{IC}_{80}$ ) also inhibit $70 \%$ of COX-1, which may explain its balanced effect against adverse cardiovascular events.

It was initially thought that diclofenac does not directly inhibit phospholipase A2 (PLA2) [10-12], but a recent study has shown that relatively high doses inhibit $93 \%$ of extra-pancreatic PLA2 in patients with acute pancreatitis $[13,14]$. This still controversial finding may be due to its different isoforms in intra- and extracellular spaces (secreted or group II PLA2s), which can promote inflammation by contributing to eicosanoid production and directly activating pro-inflammatory cells [15]. Singh et al. have shown that diclofenac inhibits $90 \%$ of the PLA2 purified from snake venom [16], and other studies have found that it also inhibits dehydrogenase and hydroxydehydrogenase enzymes, thus inactivating eicosanoid-related anti-inflammatory mediators [17] (Fig. 1).

Tonussi and Ferreira [18] used two animal models of pain to show that in addition to inhibiting COX, diclofenac apparently downregulates the function of sensitized peripheral pain receptors by stimulating the L-arginine/ nitric oxide(NO)/cyclic guanosine monophosphate (cGMP) pathway. It is known that an NOinduced increase in cGMP facilitates the opening of various ion channels $[19,20]$, and it has been shown that a cGMP analogue induces peripheral anti-nociception by activating the adenosine triphosphate(ATP)-sensitive potassium channel in rats with hyperalgesic paws induced by PGE2 [21]. Diclofenac apparently has the same effect as the diclofenac-induced activation of ATP-sensitive potassium channels can be inhibited by an NO synthase inhibitor, a guanylate cyclase inhibitor, and an ATP-sensitive potassium channel opener [22]. Diclofenac sodium (DS) may accelerate nerve regeneration and its effects on healing, as well as cause deleterious effects in the developing nerves [23] in neuropathic pain that occurs after injury and leads to dysfunction of the peripheral nervous system [23]. Furthermore, DS teratogenicity disrupts myelin sheath thickness and axon 


\section{Peripheral mechanism}

blood and synovial tissue: antinflammatory effects - COX imnhibition and PGE2 decrease

Stimulation of L-arginine NO/CGMP > downregulation of sensitised peripheral pain receptors > GGMP increased (opening of $K+$ channels)
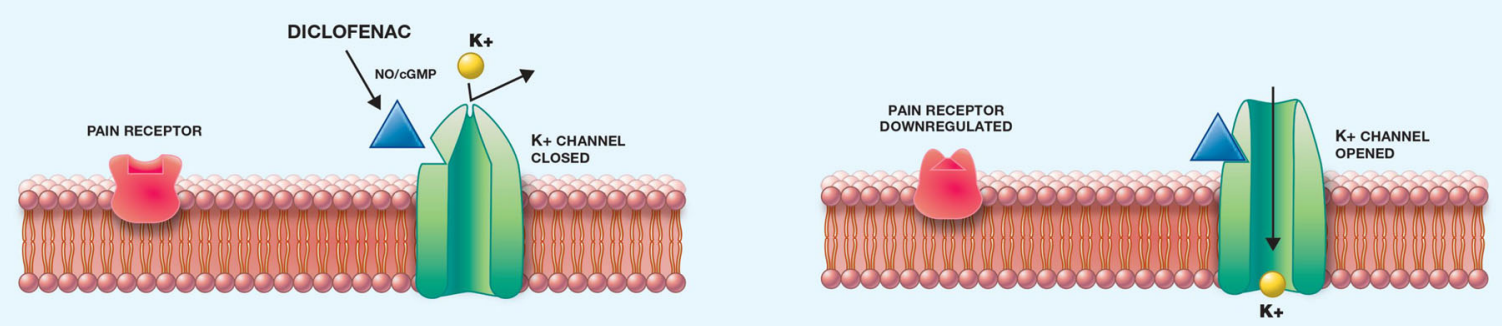

Central mechanism (spinal cord)

Beta-endorphin icreased > downregulation of NMDA receptors > analgesia

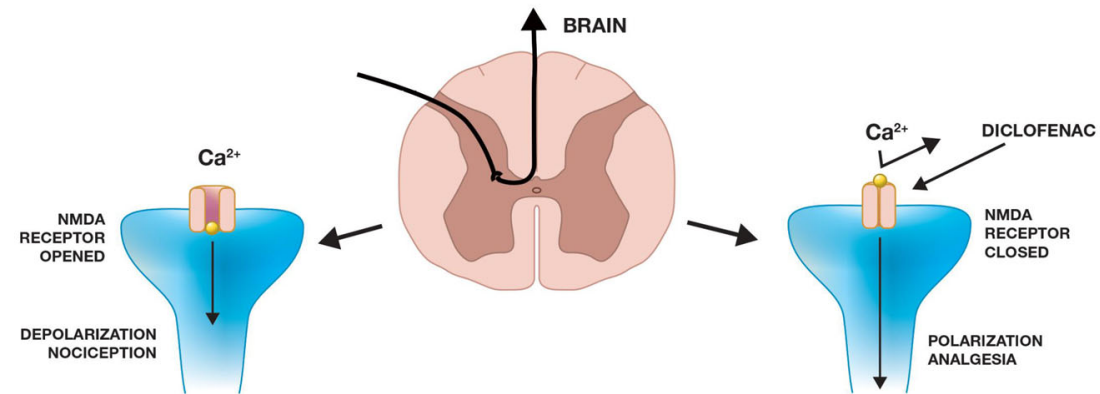

Fig. 1 Pain and old mechanisms of actions of diclofenac

structure, but its possible benefits and limitations are still unknown (Fig. 2).

\section{Central Mechanisms}

The results of animal and human studies suggest that diclofenac may act directly or indirectly on the CNS $[24,25]$. Bjorkman et al. [26] found that injecting diclofenac 1-10 ng into different areas of mouse brain dose-dependently reduced ethacrynic acid levels and induced writhing, and that diclofenac's central anti-nociceptive effects in rat could be partially reversed by naloxone, an opioid receptor antagonist. The possible role of central opioid

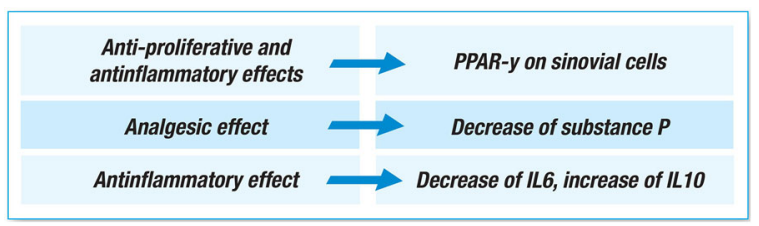

Fig. 2 Pain and new mechanisms of actions of diclofenac pathways is supported by the fact that intraperitoneally administered diclofenac decreases the concentration of pituitary $\beta$-endorphin (an endogenous opioid) in rats within 30 min [25], and this is associated with an increase in plasma $\beta$-endorphin levels (an index of nociceptive input into the CNS); it has also been reported that diclofenac increases plasma $\beta$-endorphin concentrations in humans unaffected by pain [27].

Synaptic nociceptive transmission in the spinal cord involves $N$-methyl-D-aspartate (NMDA) receptors, and it has been shown that diclofenac attenuates NMDA receptor-mediated hyperalgesia via the L-arginine/NO/cGMP pathway in rats [28], is a selective and competitive inhibitor of NMDA receptors in rat jaw muscles [29], and markedly increases rat spinal cord and diencephalon concentrations of kynurenic acid, an NMDA receptor antagonist associated with antinociceptive effects [2]. 


\section{More Recently Discovered Mechanisms}

Inflammatory processes and fatty acid metabolism involve gamma peroxisome proliferatoractivated receptors (PPAR $\gamma$ ), which also control adipocyte and macrophage differentiation, and play a role in suppressing tumor cell proliferation [8]. It has been reported that the affinity of diclofenac for PPAR $\gamma$ is 50 times greater than that of other NSAIDs, and that diclofenac acts on spinal nociceptive processing by activating $\operatorname{PPAR} \gamma$ and inhibiting prostaglandin synthesis $[2,30]$. Furthermore, as the activation of PPAR $\gamma$ suppresses microglia activation, diclofenac may be beneficial in the case of chronic neuro-inflammatory pain [31]. Yamazaki et al. [32] have shown that diclofenac increases PPAR $\gamma$ activity in the synovial cells of RA patients, and reduces cell proliferation by decreasing cell viability and inducing apoptosis. It has also been shown that PPAR $\gamma$ ligands have anti-inflammatory effects by blocking the activation of the nuclear factor kappa-light-chain-enhancer of activated B cells (NF- $\kappa \mathrm{B})$ and activation protein 1 (AP1), and can bind to specific sequences in the promoter elements of inflammatory response genes [33, 34]. Finally, diclofenac induces the release of a number of anti-inflammatory cytokines, including interleukin-10 (IL-10) and transforming growth factor- $\beta$ (TGF- $\beta$ ) via a PPAR $\gamma$ pathway in a macrophage model [35] (Fig. 3).

Substance P, a pro-inflammatory neuropeptide associated with various inflammatory diseases [36], is found in the plasma and synovial fluid of patients with arthritis. It has been hypothesized that as NSAIDs are used to treat arthritis-related pain, they may also interfere with the chemotactic effect of substance $\mathrm{P}$ on monocytes and polymorphonuclear (PMN) cells, which is a crucial step in arthritic disease. A study of RA patients has shown that diclofenac sodium $50 \mathrm{mg}$ and naproxen $250 \mathrm{mg}$ three times a day for 7 days (but not indomethacin $25 \mathrm{mg}$ ) significantly decreases synovial fluid substance P levels [2], which suggests that the analgesic effect of diclofenac may be at least partially due to the inhibition of the leukotriene pathway induced by substance $\mathrm{P}$ depletion (Fig. 4).
Initial inflammation involves a very large number of cytokines: the release of IL- 6 is regulated by prostaglandins, and its expression as well as that of other pro-inflammatory cytokines is down-regulated by IL-10. NSAIDs may reduce the levels of pro-inflammatory cytokines by means of a prostaglandin-independent mechanism because the expression and production of IL-6 is down-regulated by ketoprofen, indomethacin, and diclofenac regardless of human $\mathrm{T}$ cell PGE2 production [37], and diclofenac fully blocks the synthesis of PGE2 in human chondrocytes [38]. Major surgery patients treated with diclofenac for $12 \mathrm{~h}$ have significantly lower IL-6 and significantly higher IL-10 levels than those receiving placebo [39], and the plasma and synovial fluid IL-6 levels are significantly lowered by 7 days' diclofenac treatment of RA patients [40], and by 180 days' treatment in OA patients [41].

Tissue acidosis directly excites nociceptive sensory neurons via acid-sensing ion channels (ASICs), and thus contributes to the sensation of pain. Voilley et al. have shown that diclofenac and ibuprofen are respectively selective inhibitors of ASIC3 and ASIC1a in a simian virus 40-transformed simian cell line (COS cells), and that both prevent the inflammation-induced expression of ASICs in sensory neurons [42]. They both also inhibit proton-induced currents in rat hippocampal interneurons [43], and it has been shown that topical diclofenac decreases acid-evoked pain in humans, probably by attenuating ASIC activity [44].

\section{CHRONIC MUSCULOSKELETAL PAIN}

Osteoarthritis and rheumatoid arthritis are the most frequently encountered arthritic conditions in adults [45].

\section{Osteoarthritis}

The prevalence of OA, which is a major cause of musculoskeletal pain and the main cause of disability and handicap in Western industrialized countries, varies widely depending on the 

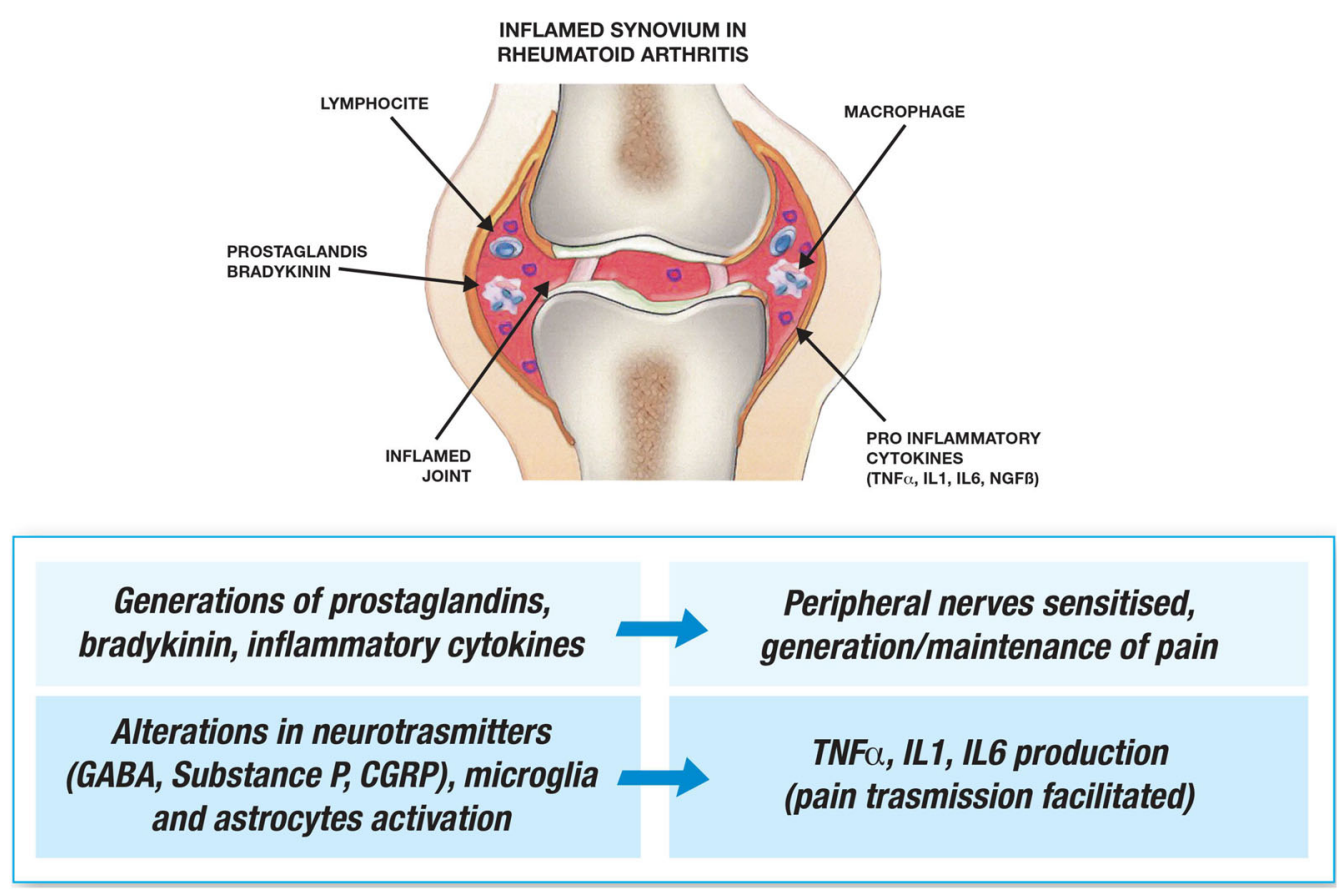

Fig. 3 Inflamed synovium-synovitis

Inflammation > pain sensitivity > inflammatory responses

Inflammation markers > matrix degradation > cartilage degeneration

Cytokines (TNF $\alpha$ ), inflammatory mediators (IL, NGF, chemokines, leukotrienes, PG, metalloproteinases) $>$ peripheral sensitisation, hyperexcitability of nociceptive neurons

Bradykinin, Substance $\boldsymbol{P}>$ hyperalgesia, allodynia

Macrophage-mediated inflammation > endothelial cells and fibroblasts stimulation

$>$ angiogenic factors $>$ angiogenesis

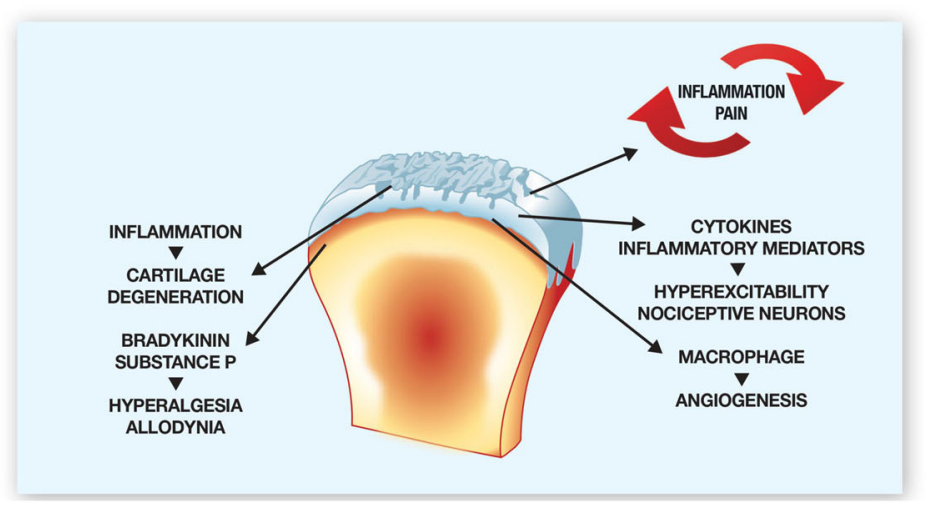

Fig. 4 Degraded cartilage 
age, gender, and geographical location of the patients and the way it is defined [46], but it has been estimated that it affected more than 26 million people in the USA in 2005 [47]. It has a severe impact on the patients' health-related quality of life (HRQoL) [48, 49], and is a considerable socio-economic burden as it leads to lost working days and early retirement, and significantly increases welfare costs.

OA-related pain is due to complex interactions between local tissue damage, inflammation, and the peripheral and central nervous systems, and is induced by nociceptive and neuropathic mechanisms $[50,51]$. Nociceptive pain arises from stimulated peripheral nociceptors, and the signals transmitted by various neurotransmitters (glutamate, aspartate, substance $P$, etc.) travel to the brain via the ascending pathway in the spinal cord [52], which they reach by means of three types of fibers. Myelinated A $\delta$ (group III) and unmyelinated C fibers (group IV) innervate the synovial membrane, joint capsule, periarticular ligaments, menisci, and the adjacent periosteum and subchondral bone, whereas myelinated $A ß$ fibers (group II) innervate the synovial membrane, joint capsule, periarticular bursae, fat pad, ligaments, menisci, and adjacent bony periosteum [21, 22]. Aß fibers are mainly activated by moving joints, whereas $\mathrm{A} \delta$ and $\mathrm{C}$ fibers are activated by means of mechanical, chemical, or thermal stimuli $[50,51]$.

$\mathrm{OA}$ is a form of non-inflammatory arthritis but, although defects in central pain processing are suggested by the fact that OA patients are sensitive to pressure at many sites, there is growing evidence that inflammation occurs because of the release of cytokines and metalloproteinases within joints [53]. It seems that is an interaction between inflammation and pain insofar as inflammation increases pain sensitivity, and this may stimulate inflammatory responses [50, 51]. The markers of joint inflammation are involved in the degraded matrix characterizing typical OA-related cartilage degeneration [53]: cytokines such as TNF, and pro-inflammatory ILs, chemokines, NGF, leukotrienes, prostaglandins, and matrix metalloproteinases initiate a cascade of events leading to peripheral sensitization. This increases the sensitivity of nociceptive primary afferent neurons, and the hyperexcitability of nociceptive neurons in the CNS [54]. Once cartilage damage has occurred, the release of bradykinin, substance $P$, and the other mediators by chondrocytes decreases nociceptive thresholds and increases neuronal membrane excitability, which causes hyperalgesia and allodynia, and therefore further contributes to the vicious circle $[50,51]$.

Macrophage-mediated inflammation can induce endothelial cells and fibroblasts to produce angiogenic factors such as vascular endothelial growth factor, and inflamed tissue hypoxia can also stimulate angiogenesis and cause further inflammation [55].

Finally, although OA-related pain is mainly a combination of nociception and local inflammation, neuropathic mechanisms may also be involved.

\section{Managing OA-Related Pain}

The Effects of NSAIDs on Nociceptive and Central Pain The management of nociceptive pain requires a sequential hierarchical approach $[56,57]$, with the initial NSAID treatment being characterized by the replacement of one drug with another, or complete discontinuation usually because of insufficient pain control [58].

A number of systematic reviews have compared the pain-reducing effects of NSAIDs and placebo $[59,60]$. One concluded that there is no clear difference among NSAIDs [61], and another, which considered 93 randomized clinical trials (RCTs), found no difference between non-selective and COX-2-selective NSAIDs [62]. A recent meta-analysis comparing the effectiveness of different NSAIDs and paracetamol found that paracetamol is clinically ineffective regardless of dose, and that diclofenac at a daily dose of $150 \mathrm{mg} /$ day is more effective in treating pain and physical disability than high doses of ibuprofen, naproxen, or celecoxib. Etoricoxib $60 \mathrm{mg} /$ day is as effective as diclofenac $150 \mathrm{mg} /$ day in treating nociceptive pain, but estimates of its effects on physical disability are imprecise, although etoricoxib $90 \mathrm{mg} /$ day and rofecoxib $50 \mathrm{mg} /$ day (both above the approved maximum daily doses) may be more effective [63]. A study by van Walsem et al. [64] found that diclofenac $150 \mathrm{mg}$ /day and 
etoricoxib $60 \mathrm{mg}$ /day were similarly effective, but the former was more effective than other NSAID regimens, including diclofenac $100 \mathrm{mg} /$ day.

However, OA-related pain is also influenced by local inflammation, and various studies have shown that central pain sensitization may develop and be maintained by an excessive nociceptive ascending input and deficient inhibitory input $[65,66]$. Moreover, changes in the regulatory tone normally governed by supraspinal descending pathways may sensitize bone marrow neurons and stimulate peripheral nociceptive signals, thus indicating that supraspinal center stimulation or reduced inhibitory activity may alter pain thresholds [66].

The role of centralized pain has been confirmed by RCTs showing the efficacy of duloxetine and tricyclic antidepressants in altering pain neurotransmitters [67], and NSAIDs can also act on this pathway. Using the experimental freeze lesion model, Burian et al. [68] found that oral diclofenac was much more effective than topical diclofenac even if tissue concentrations at the site of injury were almost the same; given the negligible systemic concentrations produced by topically applied diclofenac, they concluded that a non-peripheral (presumably central) component was involved in the antinociceptive effect of oral diclofenac. These findings suggest that diclofenac may have an effect on substance $\mathrm{P}$, which plays an important role in the CNS by sensitizing spinal neurons and causing vasodilatation, decreases nociceptive thresholds, and contributes to neurogenic inflammation in the peripheral nervous system. Furthermore, Vellani et al. [69] have shown that the up-regulated expression of preprotachykinin (PPT, a precursor of substance P) mRNA induced by inflammation in an experimental model is significantly reduced by nimesulide, paracetamol, celecoxib, and diclofenac, whereas ibuprofen is ineffective.

\section{Rheumatoid Arthritis}

RA is a frequent inflammatory joint disease that has a profound effect on the quality of life and working productivity of patients, and accounts for a considerable amount of healthcare resources [70]. Most RA patients refer to pain as their greatest problem [71], and pain may be even more disabling than structural joint damage [72]. Pain is not only a marker of the inflammation associated with disease activity, it is also a consequence of radiographically detected changes in joint structure [73].

It has been shown in clinical trials that, particularly if disease activity is regularly monitored, intensive early treatment with diseasemodifying anti-rheumatic drugs (DMARDs) and corticosteroids improve pain levels [74], although this effect may not be complete or permanent. There have also been reports of referred pain syndromes because pain intensity is not always related to disease severity or exacerbations [75].

RA-related pain may have different causes in the early and later stages of the disease, during inflammatory flares and in the intervening periods, and between one patient and another. Synovial inflammation stimulates prostaglandins, bradykinin, and pro-inflammatory cytokines such as TNF- $\alpha$, IL-1, IL- 6 , and TGF- $\beta$, which sensitize peripheral nerves and significantly contribute to generating and maintaining pain $[76,77]$. Furthermore, sensory nerves are also found in joint capsules, ligaments, the outer parts of the menisci, sub-chondral bone, tendon sheaths, and muscles [76], although the usually aneural articular cartilage and inner two-thirds of the menisci may allow pain-free joint movement and weight bearing.

Synovitis is associated with activated spinal cord microglia and astrocytes, and altered $\gamma$ aminobutyric acid (GABA), substance $P$, calcitonin gene-related peptide (CGRP) neurotransmitters, and their receptors in the spinal cord [78], which produce TNF- $\alpha$, IL-1, and IL-6, and facilitate pain transmission [77]. Transmission may be further increased by more descending activation and less descending inhibition, and central sensitization may affect more than the nerves in the inflamed joint and reduce pain thresholds in adjacent tissues [71].

\section{Managing RA-Related Pain}

The Effects of NSAIDs on Nociceptive and Central Pain Although NSAIDs are not appropriate for long-term disease control, they are often administered to RA patients in order to 
manage pain [79]. It is very important to start DMARDs promptly and, in the case of pain, the European League Against Rheumatism (EULAR) recommends NSAIDs for patients with early disease whose gastrointestinal, renal, and cardiovascular status has been carefully evaluated [79].

A systematic review of the literature describing the efficacy, safety, and tolerability of NSAIDs in 146,524 patients participating in 176 studies included in a network meta-analysis showed that diclofenac $150 \mathrm{mg}$ /day was likely to be more effective in alleviating pain than celecoxib $200 \mathrm{mg} /$ day, naproxen $1000 \mathrm{mg} /$ day, or ibuprofen $2400 \mathrm{mg} /$ day, and as effective as etoricoxib $60 \mathrm{mg} / \mathrm{day}$, and that the effect of a lower diclofenac dose of $100 \mathrm{mg} /$ day was comparable with that of all of the other treatments. The rate of major adverse cardiovascular events was similar with all of the active treatments, but diclofenac caused fewer major upper gastrointestinal events than naproxen or ibuprofen, although their frequency was similar in celecoxib-treated patients, and lower in those treated with etoricoxib [64].

Glucocorticosteroids and traditional DMARDs such as methotrexate can be used to control most cases of RA [80], and biological drugs should only be used to treat patients with very advanced or severe disease [81]. Although the analgesic effects of glucocorticosteroids may not last more than 3 months [82], the early suppression of inflammatory disease activity can avoid the development of worse pain 12 months after diagnosis, and combined DMARD treatment may be more effective than using one DMARD alone.

However, as inflammation is only one factor contributing to pain, symptomatic relief is often only partial even when the reduction in swollen joint counts and acute-phase reactant levels, and ultrasound findings show that inflammatory disease activity is under control. This means that analgesic drugs such as paracetamol are often used even though there is no supporting evidence from RCTs [83]. However, recently published recommendations from the 17-country 3e (evidence, expertise, exchange) collaborative project designed to promote evidence-based practices in rheumatology [84], many of which are based on a series of systematic Cochrane database reviews carried out in 2011-2012, suggest using paracetamol and NSAIDs to control chronic pain.

The results of clinical trials of using tricyclic antidepressants in RA patients are equivocal: one systematic Cochrane review of eight RCTs in which antidepressant therapy was compared with placebo or an active intervention found that the evidence was insufficient [85], but adjuvant tricyclic antidepressants are included in the 3e recommendations for a subset of patients with inflammatory arthritis [84]. Diclofenac can also be suggested because of its effects on substance $P, \beta$-endorphin, and NMDA receptors, and the fact that many clinical studies have demonstrated that it relieves pain. It has been shown that patients suffering from migraine who experience central sensitization with allodynia and do not achieve pain relief with other medications may benefit from the cyclooxygenase-blocking activity of diclofenac [86]. Finally, diclofenac is available for treating pain in different formulations (oral, intramuscular, topical, etc.). The sparse data available indicate that topical diclofenac can penetrate and permeate to deeper tissues, with a lower plasma-to-tissue ratio than oral diclofenac, but where it reaches a concentration that appears to be sufficient to exert a therapeutic effect [87]. Moreover, there is good evidence that some formulations of topical diclofenac and ketoprofen are useful in acute pain conditions such as sprains or strains, with low (good) numberneeded-to-treat (NNT) values, while in chronic musculoskeletal conditions with assessments over 6-12 weeks, topical diclofenac and ketoprofen had limited efficacy in hand and knee osteoarthritis, as did topical high-concentration capsaicin in postherpetic neuralgia [88]. Though NNTs were higher, this still indicates that a small proportion of people had good pain relief.

\section{ADVERSE EFFECTS}

Diclofenac has shown to be effective and is widely used in the treatment of OA and RA, but similar to other NSAIDs, is associated with an 
increased risk of serious dose-related gastrointestinal (GI), cardiovascular (CV), and renal side effects [2, 89-91]. The GI adverse events (AEs) occur due to reduced synthesis of prostanoids, limiting secretion of mucus and bicarbonate that normally protect the gastric mucosa from injury [92]. Consistent with the hypothesis that NSAIDs associated with the highest COX-1 selectivity are more likely to be associated with an increased risk of GI toxicity, diclofenac ranks low in terms of relative risk for GI complications, especially when administered at low doses ( $\leq 75 \mathrm{mg}$ daily) [93]. According to data from a meta-analysis of 280 trials of NSAIDs versus placebo $(124,513$ participants, 68,342 person-years) and 474 trials of one NSAID versus another NSAID $(229,296$ participants, 165,456 person-years), the relative risk of upper gastrointestinal complications compared with placebo was similar for diclofenac (RR 1.89) and coxibs (RR 1.81), while it was higher for ibuprofen (RR 3.97) and naproxen (RR 4.22) [91]. PGI2, a major product of COX-2-mediated metabolism of arachidonic acid in vascular endothelial cells, serves a physiologic function as a potent vasodilator and platelet inhibitor. Both preclinical and clinical evidence indicates that suppression of PGI2 synthesis increases the risk for hypertension and thrombosis. The $\mathrm{CV}$ hazard of diclofenac at doses $\geq 150 \mathrm{mg}$ daily is estimated to be comparable to that of rofecoxib and celecoxib, as well as ibuprofen administered at high doses [94]. The variable risk of myocardial infarction (MI) due to NSAIDs that do not completely inhibit COX-1 is largely related to their extent of COX-2 inhibition [2, 94]. The best safety profile related to MI was found for naproxen, while diclofenac, ibuprofen, and coxibs increased the risk. The relative risk of major coronary events compared with placebo was similar for diclofenac (RR 1,70) coxibs (RR 1,76), and ibuprofen (RR 2.22) [89]. There was only limited evidence for an increased risk of major vascular events during the first 6 months for coxibs and diclofenac [89]. Data for all other NSAIDs were not available because of the lack of well-designed RCTs [89].

Zerbini et al. [95], in a trial including 440 participants affected by chronic low back pain (LBP), which is an example of central sensitization and altered central pain processing [96], compared diclofenac $150 \mathrm{mg} /$ day versus etoricoxib $60 \mathrm{mg} /$ day for 4 weeks and found no differences in adverse events (gastrointestinal adverse events in particular) between the two cohorts [95].

\section{CONCLUSIONS}

Acute pain can frequently be attributed to mainly nociceptive inputs such as inflammation and/or peripheral structural damage, whereas chronic pain (usually defined as lasting for $\geq 3$ months) is more probably due to inputs from the central nervous system.

OA- and RA-related pain is complex and multifactorial, and due to physiological interactions between the signaling of the central and peripheral nervous systems.

The mechanisms of action of diclofenac make it particularly effective in treating both nociceptive pain and chronic central pain. Furthermore, its new mechanisms of action suggest to clinicians to change their clinical approach for treating patients with neuropathic, central sensitization and altered central pain using an old and well-known drug but able to improve the quality of the life of these cohorts of patients.

However, diclofenac has a range of actions that are of interest in an oncological context. PGE2 is formed from the break down of arachidonic acid to prostaglandin $\mathrm{H} 2$ by COX1 and COX-2 followed by further processing by microsomal prostaglandin synthase 1 (mPGES1). Elevated levels of mPGES-1 and PGE2 are found in a range of different cancer types and are associated with the chronic inflammation that is associated with a pro-tumor microenvironment [97]. Diclofenac, in common with other inhibitors of the COX enzymes, also acts to reduce PGE2 synthesis. Therefore it has other relevant mechanisms of anti-cancer action such as anti-angiogenic, immunomodulation, pro-apoptotic, platelet function, actions on Myc and glucose metabolism, and treatment sensitivity, which means that COX2 expression may correlate with sensitivity to chemotherapy or radiotherapy in different 
cancer types, which have been confirmed by pre-clinical and clinical evidence in fibrosarcoma, neuroblastoma, and colorectal cancer, etc. [97]. Moreover, it has been reported that actinic keratoses (AKs), intraepithelial atypical proliferations of keratinocytes that develop in skin that has undergone long-term exposure to ultraviolet radiation, can be treated with ingenol mebutate, imiquimod, and diclofenac, which can clear both visible and subclinical AK lesions and reduce the development of new lesions in the treated field [98]. Furthermore, the efficacy of topically applied diclofenac 3\% in combination with hyaluronic acid $2.5 \%$ in the treatment of AKs has been demonstrated in several clinical studies, even if the exact mode of action is still unclear [99]. Finally, novel antitumor platinum(II) conjugates containing the nonsteroidal anti-inflammatory agent diclofenac, a drug with antiproliferative properties typical of these metallic conjugates, is potent and cancer cell selective cytotoxic agents exhibiting activity in cisplatin resistant and the COX-2 positive tumor cell lines [100]. One of these compounds, compound 3, in which DCF molecules are coordinated to Pt(II) through their carboxylic group, is more potent than the parental conventional Pt(II) drug cisplatin, free DCF, and the congeners of 3 in which DCF ligands are conjugated to $\mathrm{Pt}(\mathrm{II})$ via a diamine. The potency of 3 is due to several factors including enhanced internalization that correlates with enhanced DNA binding and cytotoxicity [100]. Mechanistic studies show that 3 combines multiple effects. After its accumulation in cells, it releases a Pt(II) drug capable of binding/damaging DNA and DCF ligands, which affects distribution of cells in individual phases of the cell cycle, inhibits glycolysis and lactate transport, collapses mitochondrial membrane potential, and suppresses the cellular properties characteristic of metastatic progression [100].

In summary, in this review we tried to underline the mechanisms of diclofenac involved in chronic and acute joint pain, the most relevant adverse events, and future prospects of this drug in oncological field.

\section{ACKNOWLEDGEMENTS}

The authors wish to thank to Dr. Kevin Smart for the mother tongue revision.

Funding. No funding or sponsorship was received for this study or publication of this article. The article processing charges were funded by the authors.

Authorship. All named authors meet the International Committee of Medical Journal Editors (ICMJE) criteria for authorship for this article, take responsibility for the integrity of the work as a whole, and have given their approval for this version to be published.

Disclosures. Fabiola Atzeni, Ignazio Francesco Masala, and Piercarlo Sarzi-Puttini have nothing to disclose.

Compliance with Ethics Guidelines. This article is based on previously conducted studies and does not contain any studies with human participants or animals performed by any of the authors.

Data Availability. Data sharing is not applicable to this article, as no datasets were generated or analyzed during the current study.

Open Access. This article is distributed under the terms of the Creative Commons Attribution-NonCommercial 4.0 International License (http://creativecommons.org/licenses/ by-nc/4.0/), which permits any noncommercial use, distribution, and reproduction in any medium, provided you give appropriate credit to the original author(s) and the source, provide a link to the Creative Commons license, and indicate if changes were made.

\section{REFERENCES}

1. Moore RA, McQuay HJ, Derry P, et al. Single dose oral diclofenac for acute postoperative pain in adults. Cochrane Database Syst Rev. 2004;2:CD004768. 
2. Gan TJ. Diclofenac: an update on its mechanism of action and safety profile. Curr Med Res Opin. 2010;26:1715-31.

3. Vane JR, Botting RM. Mechanism of action of antiinflammatory drugs. Scand J Rheum. 1996;102:9-21.

4. Tegeder I, Lotsch J, Krebs S, et al. Comparison of inhibitory effects of meloxicam and diclofenac on human thromboxane biosynthesis after single doses and at steady state. Clin Pharmacol Ther. 1999;65:533-44.

5. Wittenberg RH, Willburger RE, Kleemeyer KS, et al. In vitro release of prostaglandins and leukotrienes from synovial tissue, cartilage, and bone in degenerative joint diseases. Arthritis Rheum. 1993;36:1444-50.

6. Ku EC, Lee W, Kothari HV, et al. Effect of diclofenac sodium on the arachidonic acid cascade. Am J Med. 1986;80:18-23.

7. Giagoudakis G, Markantonis SL. Relationships between the concentrations of prostaglandins and the nonsteroidal antiinflammatory drugs indomethacin, diclofenac, and ibuprofen. Pharmacotherapy. 2005;25:18-25.

8. Tegeder I, Pfeilschifter J, Geisslinger G. Cyclooxygenase-independent actions of cyclooxygenase inhibitors. FASEB J. 2001;15:2057-72.

9. Warner TD, Giuliano F, Vojnovic I, et al. Nonsteroid drug selectivities for cyclooxygenase- 1 rather than cyclo-oxygenase- 2 are associated with human gastrointestinal toxicity: a full in vitro analysis. Proc Natl Acad Sci USA. 1999;96:7563-8.

10. Dennis EA. Diversity of group types, regulation, and function of phospholipase A2. J Biol Chem. 1994;269:13057-60.

11. Walsh CE, Dechatelet LR, Thomas MJ, et al. Effect of phagocytosis and ionophores on release and metabolism of arachidonic acid from human neutrophils. Lipids. 1981;16:120-4.

12. Kothari HV, Lee WH, Ku EC. An alternate mechanism for regulation of leukotriene production in leukocytes: studies with an anti-inflammatory drug, sodium diclofenac. Biochim Biophys Acta. 1987;921:502-11.

13. Nevalainen TJ, Gronroos JM, Kortesuo PT. Pancreatic and synovial type phospholipases A2 in serum samples from patients with severe acute pancreatitis. Gut. 1993;34:1133-6.

14. Makela A, Kuusi T, Schroder T. Inhibition of serum phospholipase-A2 in acute pancreatitis by pharmacological agents in vitro. Scand J Clin Lab Invest. 1997;57:401-7.

15. Triggiani M, Granata F, Frattini A, et al. Activation of human inflammatory cells by secreted phospholipases A2. Biochim Biophys Acta. 2006;1761:1289-300.

16. Singh N, Jabeen T, Sharma S, et al. Specific binding of non-steroidal anti-inflammatory drugs (NSAIDs) to phospholipase A2: structure of the complex formed between phospholipase A2 and diclofenac at $2.7 \mathrm{~A}^{\circ}$ resolution. Acta Crystallogr D. 2006;62:410-6.

17. Clish CB, Sun YP, Serhan CN. Identification of dual cyclooxygenase-eicosanoid oxidoreductase inhibitors: NSAIDs that inhibit PG-LX reductase/LTB(4) dehydrogenase. Biochem Biophys Res Commun. 2001;288:868-74.

18. Tonussi CR, Ferreira SH. Mechanism of diclofenac analgesia: direct blockade of inflammatory sensitization. Eur J Pharmacol. 1994;251:173-9.

19. Fagni L, Bockaert J. Effects of nitric oxide on glutamate-gated channels and other ionic channels. J Chem Neuroanatomy. 1996;10:231-40.

20. Armstead WM. Role of ATP-sensitive Kp channels in cGMP-mediated pial artery vasodilation. Am J Physiol. 1996;270:H423-6.

21. Soares AC, Duarte ID. Dibutyryl-cyclic GMP induces peripheral antinociception via activation of ATPsensitive $K(p)$ channels in the rat PGE2-induced hyperalgesic paw. Br J Pharmacol. 2001;134:127-31.

22. Alves DP, Tatsuo MA, Leite R, et al. Diclofenac-induced peripheral antinociception is associated with ATP-sensitive $\mathrm{Kp}$ channels activation. Life Sci. 2004;74:2577-91.

23. Kaplan AA, Yurt KK, Deniz ÖG, Altun G. Peripheral nerve and diclofenac sodium: Molecular and clinical approaches. J Chem Neuroanat. 2018;87:2-11.

24. Okuyama S, Aihara H. The mode of action of analgesic drugs in adjuvant arthritic rats as an experimental model of chronic inflammatory pain: possible central analgesic action of acidic nonsteroidal antiinflammatory drugs. Jpn J Pharmacol. 1984;35:95-103.

25. Sacerdote P, Monza G, Mantegazza P, et al. Diclofenac and pirprofen modify pituitary and hypothalamic beta-endorphin concentrations. Pharmacol Res Commun. 1985;17:679-84.

26. Bjorkman RL, Hedner T, Hallman KM, et al. Localization of the central antinociceptive effects of diclofenac in the rat. Brain Res. 1992;590:66-73. 
27. Martini A, Bondiolotti GP, Sacerdote P, et al. Diclofenac increases beta-endorphin plasma concentrations. J Int Med Res. 1984;12:92-5.

28. Bjorkman R, Hallman KM, Hedner J, et al. Nonsteroidal antiinflammatory drug modulation of behavioral responses to intrathecal $\mathrm{N}$-methyl-D-aspartate, but not to substance $\mathrm{P}$ and amino-methylisoxazole-propionic acid in the rat. J Clin Pharmacol. 1996;36:20S-6S.

29. Dong X-D. The analgesic action of topical diclofenac may be mediated through peripheral NMDA receptor antagonism. Pain. 2009;147:36-45.

30. Adamson DJ, Frew D, Tatoud R, Wolf CR, Palmer $\mathrm{CN}$. Diclofenac antagonizes peroxisome proliferator-activated receptor-gamma signaling. Mol Pharmacol. 2002;61:7-12.

31. Gehrmann J, Matsumoto Y, Kreutzeberg GW. Microglia: intrinsic immunoeffector cell of the brain. Brain Res Rev. 1995;20:269-87.

32. Yamazaki R, Kusunoki N, Matsuzaki T, et al. Nonsteroidal anti-inflammatory drugs induce apoptosis in association with activation of peroxisome proliferator-activated receptor gamma in rheumatoid synovial cells. J Pharmacol Exp Ther. 2002;302:18-25.

33. Na HK, Surh YJ. Peroxisome proliferator-activated receptor gamma (PPARgamma) ligands as bifunctional regulators of cell proliferation. Biochem Pharmacol. 2003;66:1381-91.

34. Sandri A. Spinal anti-inflammatory action of diclofenac. Minerva Med. 2016;107:167-72.

35. Ayoub SS, Botting RM, Joshi AN, et al. Activation of macrophage peroxisome proliferator-activated receptor-gamma by diclofenac results in the induction of cyclooxygenase- 2 protein and the synthesis of anti-inflammatory cytokines. Mol Cell Biochem. 2009;327:101-10.

36. O'Connor TM, O'Connell J, O'Brien DI, et al. The role of substance $\mathrm{P}$ in inflammatory disease. J Cell Phys. 2004;201:167-80.

37. Tsuboi I, Tanaka H, Nakao M, et al. Nonsteroidal anti-inflammatory drugs differentially regulate cytokine production in human lymphocytes: upregulation of TNF, IFN-gamma and IL-2, in contrast to down-regulation of IL-6 production. Cytokine. 1995;7:372-9.

38. Henrotin $\mathrm{Y}$, de Leval $\mathrm{X}$, Mathy-Hartet $\mathrm{M}$, et al. In vitro effects of aceclofenac and its metabolites on the production by chondrocytes of inflammatory mediators. Inflamm Res. 2001;50:391-9.
39. Mahdy AM, Galley HF, Abdel-Wahed MA, et al. Differential modulation of interleukin-6 and interleukin-10 by diclofenac in patients undergoing major surgery. Br J Anaesth. 2002;88:797-802.

40. Sacerdote P, Carrabba M, Galante A, et al. Plasma and synovial fluid interleukin-1, interleukin- 6 and substance $\mathrm{P}$ concentrations in rheumatoid arthritis patients: effect of the nonsteroidal anti-inflammatory drugs indomethacin, diclofenac and naproxen. Inflamm Res. 1995;44:486-90.

41. Gonzalez E, de la Cruz C, de Nicolas R, et al. Longterm effect of nonsteroidal anti-inflammatory drugs on the production of cytokines and other inflammatory mediators by blood cells of patients with osteoarthritis. Agents Actions. 1994;41:171-8.

42. Voilley N, de Weille J, Mamet J, et al. Nonsteroid anti-inflammatory drugs inhibit both the activity and the inflammation-induced expression of acid sensing ion channels in nociceptors. J Neurosci. 2001;21:8026-33.

43. Dorofeeva NA, Barygin OI, Staruschenko A, et al. Mechanisms of non-steroid anti-inflammatory drugs action on ASICs expressed in hippocampal interneurons. J Neurochem. 2008;106:429-41.

44. Jones NG, Slater R, Cadiou $\mathrm{H}$, et al. Acid-induced pain and its modulation in humans. J Neurosci. 2004;24:10974-9.

45. Sangha O. Epidemiology of rheumatic diseases. Rheumatology (Oxford). 2000;39:3-12.

46. Litwic A, Edwards MH, Dennison EM, Cooper C. Epidemiology and burden of osteoarthritis. Br Med Bull. 2013;105:185-99.

47. Lawrence RC, Felson DT, Helmick CG, Arnold LM, Choi H, Deyo RA, et al. Estimates of the prevalence of arthritis and other rheumatic conditions in the United States. Part II. Arthritis Rheum. 2008;58:26-35.

48. Salaffi F. Pain in osteoarthritis: assessment and impact on the disability. Reumatismo. 2003;55(4):19-37.

49. Salaffi F, Carotti M, Stancati A, Grassi W. Healthrelated quality of life in older adults with symptomatic hip and knee osteoarthritis: a comparison with matched healthy controls. Aging Clin Exp Res. 2005;17(4):255-63.

50. Mease PJ, Hanna S, Frakes EP, Altman RD. Pain mechanisms in osteoarthritis: understanding the role of central pain and current approaches to its treatment. J Rheumatol. 2011;38:1546-51. 
51. Dray A, Read SJ. Arthritis and pain. Future targets to control osteoarthritis pain. Arthritis Res Ther. 2007;9:212.

52. Schaible HG, Schmelz M, Tegeder I. Pathophysiology and treatment of pain in joint disease. Adv Drug Deliv Rev. 2006;58:323-42.

53. Salaffi F, Ciapetti A, Carotti M. The sources of pain in osteoarthritis: a pathophysiological review. Reumatismo. 2014;66:57-71.

54. Schaible HG, Ebersberger A, von Banchet GS. Mechanisms of pain in arthritis. Ann N Y Acad Sci. 2002;966:343-54.

55. Bonnet CS, Walsh DA. Osteoarthritis, angiogenesis and inflammation. Rheumatology. 2005;44:7-16.

56. Porcheret M, Jordan K, Jinks C, Croft P. Primary care treatment of knee pain-a survey in older adults. Rheumatology (Oxford). 2007;46:1694-700.

57. Juni P, Reichenbach S, Dieppe P. Osteoarthritis: rational approach to treating the individual. Best Pract Res Clin Rheumatol. 2006;20:721-40.

58. Gore M, Sadosky A, Leslie D, Tai KS, Seleznick M. Patterns of therapy switching, augmentation, and discontinuation after initiation of treatment with select medications in patients with osteoarthritis. Clin Ther. 2011;33:1914-31.

59. McAlindon TE, Bannuru RR, Sullivan MC, et al. OARSI guidelines for the non-surgical management of knee osteoarthritis. Osteoarthritis Cartilage. 2014;22:363-88.

60. Bjordal JM, Klovning A, Ljunggren AE, Slordal L. Short-term efficacy of pharmacotherapeutic interventions in osteoarthritic knee pain: A meta-analysis of randomised placebo-controlled trials. Eur J Pain. 2007;11(2):125-38.

61. Chen YF, Jobanputra P, Barton P, et al. Cyclooxygenase-2 selective non-steroidal anti-inflammatory drugs (etodolac, meloxicam, celecoxib, rofecoxib, etoricoxib, valdecoxib and lumiracoxib) for osteoarthritis and rheumatoid arthritis: a systematic review and economic evaluation. Health Technol Assess. 2008;12:1-278.

62. Chou R, McDonagh MS, Nakamoto E, Griffin J. Analgesics for osteoarthritis: an update of the 2006 comparative effectiveness review. Rockville: Agency for Healthcare Research and Quality (US), 2011.

63. da Costa BR, Reichenbach S, Keller N, Nartey L, Wandel S, Jüni P, Trelle S. Effectiveness of nonsteroidal anti-inflammatory drugs for the treatment of pain in knee and hip osteoarthritis: a network meta-analysis. Lancet. 2016;387(10033):2093-105.
64. van Walsem A, Pandhi S, Nixon RM, Guyot P, Karabis A, Moore RA. Relative benefit-risk comparing diclofenac to other traditional non-steroidal anti-inflammatory drugs and cyclooxygenase- 2 inhibitors in patients with osteoarthritis or rheumatoid arthritis: a network meta-analysis. Arthritis Res Ther. 2015;17:66.

65. Latremoliere A, Woolf CJ. Central sensitization: a generator of pain hypersensitivity by central neural plasticity. J Pain. 2009;10:895-926.

66. Treede RD, Kenshalo DR, Gracely RH, Jones AK. The cortical representation of pain. Pain. 1999;79:105-11.

67. Phillips K, Clauw DJ. Central pain mechanism in the rheumatic diseases. Arth Rheum. 2013;65:291-302.

68. Burian M, Tegeder I, Seegel M, Geisslinger G. Peripheral and central antihyperalgesic effects of diclofenac in a model of human inflammatory pain. Clin Pharmacol Ther. 2003;74:113-20.

69. Vellani V, Franchi S, Prandini M, Moretti S, Castelli M, Giacomoni C, Sacerdote P. Effects of NSAIDs and paracetamol (acetaminophen) on protein kinase $\mathrm{C}$ epsilon translocation and on substance P synthesis and release in cultured sensory neurons. J Pain Res. 2013;6:111-20.

70. Kazis LE, Meenan RF, Anderson JJ. Pain in the rheumatic diseases. Investigation of a key health status component. Arthritis Rheum. 1983;26:1017-22.

71. Atzeni F, Masala IF, Salaffi F, Di Franco M, Casale R, Sarzi-Puttini P. Pain in systemic inflammatory rheumatic diseases. Best Pract Res Clin Rheumatol. 2015;29(1):42-52.

72. Odegard S, Finset A, Mowinckel P, Kvien TK, Uhlig T. Pain and psychological health status over a 10-year period in patients with recent onset rheumatoid arthritis. Ann Rheum Dis. 2007;66:1195-201.

73. Atzeni F, Sarzi-Puttini P. Rheumatoid arthritis: why wait? Explaining delays in seeking therapy for early arthritis. Nat Rev Rheumatol. 2012;8:190-1.

74. Andersson ML, Svensson B, Bergman S. Chronic widespread pain in patients with rheumatoid arthritis and the relation between pain and disease activity measures over the first 5 years. J Rheumatol. 2013;40:1977-85.

75. Atzeni F, Cazzola M, Benucci M, Di Franco M, Salaffi F, Sarzi-Puttini P. Chronic widespread pain in the spectrum of rheumatological diseases. Best Pract Res Clin Rheumatol. 2011;25:165-71. 
76. Woolf CJ. Central sensitization: implications for the diagnosis and treatment of pain. Pain. 2010;152:S2-15.

77. Raychaudhuri SP, Raychaudhuri SK, Atkuri KR, Herzenberg LA, Herzenberg LA. Nerve growth factor: a key local regulator in the pathogenesis of inflammatory arthritis. Arthritis Rheum. 2011;63:3243-52.

78. Schaible HG, von Banchet GS, Boettger MK, et al. The role of proinflammatory cytokines in the generation and maintenance of joint pain. Ann N Y Acad Sci. 2010;1193:60-9.

79. Sarzi-Puttini P, Atzeni F, Lanata L, Bagnasco M. Efficacy of ketoprofen vs. ibuprofen and diclofenac: a systematic review of the literature and metaanalysis. Clin Exp Rheumatol. 2013;31(5):731-8.

80. Boers M, Verhoeven AC, Markusse HM, et al. Randomized comparison of combined step-down prednisolone, methotrexate, and sulphasalazine with sulphasalazine alone in early rheumatoid arthritis. Lancet. 1997;350:309-18.

81. Emery P. Optimizing outcomes in patients with rheumatoid arthritis and an inadequate response to anti-TNF treatment. Rheumatology. 2012;51(Suppl 5):v22-30.

82. Ramiro S, Radner H, van der Heijde D, et al. Combination therapy for pain management in inflammatory arthritis (rheumatoid arthritis, ankylosing spondylitis, psoriatic arthritis, other spondyloarthritis). Cochrane Database Syst Rev. 2011;(10):CD008886.

83. Wienecke T, Gotzsche PC. Paracetamol vs nonsteroidal anti-inflammatory drugs for rheumatoid arthritis. Cochrane Database Syst Rev. 2004;1:CD003789.

84. Whittle SL, Colebatch AN, Buchbinder R, et al. Multinational evidence-based recommendations for pain management by pharmacotherapy in inflammatory arthritis: integrating systematic literature research and expert opinion of a broad panel of rheumatologists in the 3e initiative. Rheumatology (Oxford). 2012;51:1416-25.

85. Richards BL, Whittle SL, Buchbinder R. Neuromodulators for pain management in rheumatoid arthritis. Cochrane Database Syst Rev. 2012;1:CD008921.

86. Joshi S, Rapoport AM. Diclofenac potassium for oral solution $\left(\mathrm{CAMBIA}^{\circledR}\right)$ in the acute management of a migraine attack: clinical evidence and practical experience. Ther Adv Neurol Disord. 2017;10(4):217-26.
87. Hagen M, Baker M. Skin penetration and tissue permeation after topical administration of diclofenac. Curr Med Res Opin. 2017;33:1623-34.

88. Derry S, Wiffen PJ, Kalso EA, et al. Topical analgesics for acute and chronic pain in adults-an overview of Cochrane Reviews. Cochrane Database Syst Rev. 2017;5:CD008609.

89. Coxib and traditional NSAID Trialists' (CNT) Collaboration Vascular and upper gastrointestinal effects of non-steroidal anti-inflammatory drugs: meta-analyses of individual participant data from randomised trials. Lancet. 2013;382:769-79.

90. Kuo HW, Tsai SS, Tiao MM, Liu YC, Lee IM, Yang $\mathrm{CY}$. Analgesic use and the risk for progression of chronic kidney disease. Pharmacoepidemiol Drug Saf. 2010;19:745-51.

91. Kontogiorgis C, Valikeserlis I, Hadjipavlou-Litina D, Nena E, Constantinidis TC. Use of non-selective non-steroidal anti-inflammatory drugs in relation to cardiovascular events. A systematic pharmacoepidemiological review. Curr Vasc Pharmacol. 2016;14:502-13.

92. Warner TD, Giuliano F, Vojnovic I, Bukasa A, Mitchell JA, Vane JR. Nonsteroid drug selectivities for cyclo-oxygenase-1 rather than cyclo-oxygenase2 are associated with human gastrointestinal toxicity: a full in vitro analysis. Proc Natl Acad Sci. 1999;96:7563-8.

93. Laporte JR, Ibanez L, Vidal X, Vendrell L, Leone R. Upper gastrointestinal bleeding associated with the use of NSAIDs: newer versus older agents. Drug Saf. 2004;27:411-20.

94. Altman R, Bosch B, Brune K, Patrignani P, Young C. Advances in NSAID development: evolution of diclofenac products using pharmaceutical technology. Drugs. 2015;75:859-77.

95. Zerbini C, Ozturk ZE, Grifka J, Maini M, Nilganuwong $\mathrm{S}$, Morales $\mathrm{R}$, et al. Efficacy of etoricoxib $60 \mathrm{mg} /$ day and diclofenac $150 \mathrm{mg} /$ day in reduction of pain and disability in patients with chronic low back pain: results of a 4 -week, multinational, randomized, double-blind study. Curr Med Res Opin. 2005;21(12):2037-49.

96. Roussel NA, Nijs J, Meeus M, Mylius V, Fayt C, Oostendorp R. Central sensitization and altered central pain processing in chronic low back pain: fact or myth? Clin J Pain. 2013;29(7):625-38.

97. Pantziarka P, Sukhatme V, Bouche G, Meheus L, Sukhatme VP. Repurposing Drugs in Oncology (ReDO)-diclofenac as an anti-cancer agent. Ecancermedicalscience. 2016;10:610. 
98. Stockfleth E. The importance of treating the field in actinic keratosis. J Eur Acad Dermatol Venereol. 2017;31(Suppl 2):8-11.

99. Maltusch A, Röwert-Huber J, Matthies C, LangeAsschenfeldt S, Stockfleth E. Modes of action of diclofenac 3\%/hyaluronic acid $2.5 \%$ in the treatment of actinic keratosis. J Dtsch Dermatol Ges. 2011;9(12):1011-7.
100. Intini FP, Zajac J, Novohradsky V, Saltarella T, Pacifico C, Brabec V, Natile G, Kasparkova J. Novel antitumor platinum(II) conjugates containing the nonsteroidal anti-inflammatory agent diclofenac: synthesis and dual mechanisms of antiproliferative effects. Inorg Chem. 2017;56(3):1483-97. 